\title{
A ESCRITA DA REDAÇÃO DO ENEM POR UMA ALUNA HAITIANA: MOBILIZANDO AS CAPACIDADES DE SIGNIFICAÇÃO
}

\author{
THE WRITING OF THE ENEM ESSAY BY A HAITIAN STUDENT: \\ MOBILIZING THE SIGNIFICATION CAPACITIES
}

Desirée de Almeida Oliveira*

\begin{abstract}
RESUMO
Neste artigo, analisamos registros gerados em um estudo no contexto do projeto Pró-Imigrantes, que visa oferecer aulas preparatórias gratuitas para o Exame Nacional do Ensino Médio (Enem) a refugiados e outros imigrantes potencialmente em situação de vulnerabilidade, residentes em Belo Horizonte $(\mathrm{MG})$ e região metropolitana. Especificamente, analisamos três produções textuais, referentes à redação do Enem, elaboradas por uma aluna de nacionalidade haitiana e falante de português como língua adicional. Na análise, centramo-nos na mobilização das capacidades de significação (CRISTOVÃO; STUTZ, 2011) no processo de construção da argumentação. Esta pesquisa-ação, conduzida em sala de aula, embasa-se no arcabouço teórico do Interacionismo Sociodiscursivo (BRONCKART, 1999), no construto de capacidades de linguagem (DOLZ; PASQUIER; BRONCKART, 1993), na concepção de sequência didática (DOLZ; NOVERRAZ; SCHNEUWLY, 2011) e em noções sobre a redação do Enem (BRASIL, 2016; OLIVEIRA, 2019). A análise evidencia que, ao mobilizar as capacidades de significação, desenvolvidas no decorrer da implementação da sequência didática, a aluna fortaleceu, de modo expressivo, a argumentação nas produções textuais. As discussões sobre os resultados obtidos também contribuem para a área de Português como Língua de Acolhimento.
\end{abstract}

Palavras-chave: capacidades de significação; Português como Língua de Acolhimento; redação do Enem.

\section{ABSTRACT}

In this article, we analyze records generated in a study within the context of the Pró-Imigrantes project, which aims to offer free preparatory classes for the Exame Nacional do Ensino Médio (Enem) to refugees and other potentially vulnerable immigrants who reside in Belo Horizonte (MG) and in its metropolitan area. Specifically, we analyze three text productions of the Enem essay elaborated by a Haitian student who speaks Portuguese as an additional language. In the analysis, we focus on the mobilization of the signification capacities (CRISTOVÃO; STUTZ, 2011) in the process of argument construction. This classroom action research is based on the theoretical framework of Socio-discursive Interactionism (BRONCKART, 1999), on the construct of language capacities (DOLZ; PASQUIER; BRONCKART, 1993), on the concept of didactic sequence (DOLZ; NOVERRAZ; SCHNEUWLY, 2011), and on notions about the Enem essay (BRASIL, 2016; OLIVEIRA, 2019). The analysis shows that, by mobilizing the signification capacities, developed during the implementation of the didactic sequence, the student strengthened her arguments considerably in the text productions. The discussions about the results obtained also contribute to the area of Portuguese as a Welcoming Language.

Keywords: signification capacities; Portuguese as a Welcoming Language; Enem essay.

\section{INTRODUÇÃO}

Neste estudo', analisamos a mobilização das capacidades de significação (CRISTOVÃO; STUTZ, 2011) para a construção da argumentação nas produções textuais elaboradas por uma aluna, de nacionalidade haitiana e falante de português como língua adicional, em preparação para a prova de redação do Exame Nacional do Ensino Médio (Enem). As aulas de redação ocorreram em 2017 no contexto do projeto Pró-Imigrantes, criado em 2015, com o objetivo de oferecer um curso preparatório gratuito para o Enem a refugiados e outros imigrantes potencialmente em situação de vulnerabilidade, residentes em Belo Horizonte (MG) e região metropolitana. Os professores do projeto são voluntários e ministram aulas de biologia, física, geografia, história, linguagens, matemática, química e redação, as quais ocorrem de segunda a sexta-feira, das $19 \mathrm{~h}$ às $22 \mathrm{~h}$, em uma sala disponibilizada no campus da Universidade Federal de Minas Gerais. De 2015 a 2019, o projeto contou com o apoio da Diretoria de Relações Internacionais da

\footnotetext{
* Doutora pelo Programa de Pós-Graduação em Estudos Linguísticos da Universidade Federal de Minas Gerais, UFMG, Belo Horizonte, MG, Brasil.desiree oliveira@outlook.com

Orcid: https://orcid.org/0000-0001-9802-3208

1. Este trabalho é um recorte da tese de doutorado intitulada "A preparação de imigrantes haitianos para a produção da redação do Enem" (OLIVEIRA, 2019), defendida por Desirée de Almeida Oliveira no Programa de Pós-Graduação em Estudos Linguísticos da Universidade Federal de Minas Gerais, sob a orientação da Profa. Dra. Luciane Corrêa Ferreira e coorientação do Prof. Dr. Leandro Rodrigues Alves Diniz.
} 
instituição e, em 2020, tornou-se um projeto vinculado à Pró-Reitoria de Extensão, sendo, atualmente, coordenado pela Profa. Dra. Luciane Corrêa Ferreira, da Faculdade de Letras.

O projeto Pró-Imigrantes, em particular no tocante às aulas de redação, caracteriza-se pelo ensino e aprendizagem de Português como Língua de Acolhimento (PLAc), termo que, embora problematizado (BIZON; CARMARGO, 2018; CAMARGO, 2019; LOPEZ; DINIZ, 2018; LOPEZ, 2016), é amplamente utilizado para se referir ao ensino e aprendizagem da língua portuguesa em contexto de migração forçada ou de crise, a qual tem aumentado consideravelmente no mundo e resultado na vinda de milhares de migrantes para o Brasil (ACNUR, 2020; SILVA et al., 2020). Lopez e Diniz (2018, p. 37) conceituam o PLAc como uma ramificação da subárea de Português como Língua Adicional, integrante da área de Linguística Aplicada, que "se dedica à pesquisa e ao ensino de português para imigrantes, com destaque para deslocados forçados, que estejam em situação de vulnerabilidade e que não tenham o português como língua materna." Os autores assinalam que o objetivo "é a circulação de saberes linguístico-discursivos que, em última instância, contribuam para 'produzir e democratizar mobilidades e multiterritorialidades', fazendo face a processos de 'reterritorialização precária'" (BIZON, 2013, p. 123).

No caso dos alunos do projeto Pró-Imigrantes, fazer frente a processos de reterritorialização precária, produzindo e democratizando mobilidades e multiterritorialidades, envolve, entre outros aspectos, a apropriação de saberes linguístico-discursivos diretamente relacionados à redação do Enem, os quais são necessários para o ingresso no ensino superior e representam a possibilidade de integração mais plena no país de acolhimento. Uma vez que o contexto de migração de crise é bastante heterogêneo, Camargo (2019, p. 180) ressalta que "ensinar português para acolher, no sentido de propiciar processos de reterritorialização, é uma atitude que deve ser responsiva às demandas dos migrantes de crise em vez de ser pré-determinada por quem acolhe." Sendo assim, a autora salienta que o PLAc não deve ser entendido como o ensino e a aprendizagem da língua portuguesa apenas para atender a necessidades de contato inicial ou emergencial com a sociedade de acolhimento, mas também como o ensino e a aprendizagem da língua para fins específicos, tais quais os de preparação para exames como o Enem e o Celpe-Bras (Certificado de Proficiência em Língua Portuguesa para Estrangeiros), entre outras finalidades que se mostrem condizentes com as necessidades e interesses dos próprios migrantes de crise.

Com o desafio de intervir pedagogicamente, a professora de redação do projeto elaborou e implementou um dispositivo semelhante à sequência didática (DOLZ; NOVERRAZ; SCHNEUWLY, 2011), embasado nos princípios do Interacionismo Sociodiscursivo (BRONCKART, 1999) e orientado para o desenvolvimento das capacidades de linguagem (DOLZ; PASQUIER; BRONCKART, 1993), a fim de contribuir para que os alunos se apropriassem das características da redação do Enem e ampliassem seus conhecimentos sobre a língua portuguesa - para eles, um idioma adicional -, bem como sobre temáticas que pudessem ser abordadas nas produções textuais.

O corpo discente total era formado por três alunos de nacionalidade haitiana, que visavam dar continuidade aos seus estudos por meio da realização do Enem e posterior candidatura a vagas de ensino superior em universidades no Brasil. A professora de redação, também coordenadora voluntária do projeto, tinha experiência de mais de seis anos como professora de Português como Língua Adicional e familiaridade com a vertente de ensino de Português como Língua de Acolhimento. Durante o curso, teve sua primeira experiência com aulas preparatórias para o referido exame e procurou articular seus conhecimentos prévios sobre a aprendizagem de línguas à aprendizagem da redação do Enem enquanto gênero textual.

Em um primeiro momento, a professora elaborou um modelo didático de gênero para a redação do Enem, com o intuito de identificar suas dimensões ensináveis e obter subsídios para planejar as atividades da sequência didática (SCHNEUWLY; DOLZ, 2011). A construção do modelo, com base no modelo de análise textual do Interacionismo Sociodiscursivo (ISD) (BRONCKART, 1999), revelou que a situação de produção do gênero é bastante restrita, pois se limita a objetivos e interlocutores que remetem à esfera escolar. Já o conteúdo temático é bastante amplo, podendo abranger questões de ordem social, política, científica e cultural. Devido à sua natureza dissertativo-argumentativa, a redação do Enem deve apresentar uma tese (opinião ou ponto de vista) sobre o tema abordado, a qual será defendida ao longo do texto por meio de estratégias argumentativas, também devendo apresentar uma proposta de intervenção que ajude a solucionar os problemas apontados (BRASIL, 2016; OLIVEIRA, 2019). O discurso teórico, as sequências textuais argumentativas, os organizadores lógico-argumentativos, as anáforas nominais, as vozes sociais e as modalizações deônticas predominam no gênero (OLIVEIRA, 2019).

Este trabalho está organizado em cinco seções, sendo a primeira esta introdução. Em seguida, passamos à fundamentação teórica, abordando o ISD, as capacidades de linguagem e a concepção de gênero textual. Logo após, 
traçamos o delineamento metodológico do estudo, realizamos a análise dos registros gerados e apresentamos as considerações finais.

\section{FUNDAMENTAÇÃO TEÓRICA}

Na perspectiva teórica do ISD, as condutas verbais constituem formas de ação resultantes "da apropriação, pelo organismo humano, das propriedades da atividade social mediada pela linguagem" (BRONCKART, 1999, p. 42). A partir dessa perspectiva, originam-se as concepções de atividade de linguagem e ação de linguagem, as quais diferem entre si por enfatizarem, respectivamente, a dimensão coletiva (ordem sociológica) e individual (ordem psicológica) do agir humano. A ação de linguagem constitui parte da atividade de linguagem, no sentido de que se refere ao conjunto de representações que um indivíduo específico constrói sobre a sua participação na atividade. (BRONCKART, 1999, 2006).

A ação de linguagem se concretiza por meio de textos, orais e escritos, que se inscrevem em determinados gêneros, ou seja, em conjuntos de textos que apresentam características em comum, mas que não constituem padrões para serem simplesmente imitados ou reproduzidos. Visto que o propósito é atender as necessidades comunicativas da sociedade, os gêneros textuais são de caráter histórico e cultural, não permanecendo estáticos e imutáveis, podendo um gênero dar origem a outro ou surgir como desmembramento de outros (MARCUSCHI, 2011). A partir de parâmetros da situação de comunicação que guiam a ação de linguagem, o produtor seleciona o gênero textual mais adequado para seus objetivos, adaptando-o em um processo que torna cada texto singular e contribui para a transformação do gênero a curto, médio e/ou longo prazo (MACHADO, 2003).

Para melhor compreender os diferentes gêneros textuais, o ISD propõe um modelo de análise em dois níveis: as condições de produção e a arquitetura textual. O primeiro se refere às representações, na mente do indivíduo, sobre o quadro físico da ação (emissor/coemissor e espaço/tempo de produção), o quadro sociossubjetivo (tipo e objetivo da interação social e papel social do emissor/enunciador e receptor/destinatário) e os conhecimentos sobre a temática do texto. Já o segundo é dividido em três subníveis: infraestrutura (plano geral, tipos de discurso e tipos de sequência textual), coerência temática (conexão, coesão nominal e coesão verbal) e coerência pragmática (gestão de vozes e modalizações) (BRONCKART, 1999).

O agente pode adquirir e ampliar conhecimentos quanto à produção de determinado gênero textual por meio do desenvolvimento das capacidades de linguagem, definidas como "aptidões requeridas para a realização de um texto ${ }^{2}$ em uma situação de interação determinada" (DOLZ; PASQUIER, BRONCKART, 1993, p. 30, tradução nossa) ${ }^{3}$. O desenvolvimento das capacidades de linguagem não ocorre de modo linear ou cumulativo, mas de forma espiralada em razão do processo de construção em situações complexas de comunicação (DOLZ; GAGNON, DECÂNDIO, 2010, p. 18). Sendo assim, no decorrer da escolaridade, um mesmo gênero pode ser trabalhado repetidas vezes, de acordo com níveis de complexidade e graus de aprofundamento crescentes (DOLZ; SCHNEUWLY, 2011).

As seguintes capacidades de linguagem são identificadas: 1) as capacidades de ação, compreendidas como "aptidões para adaptar a situação linguageira às características do contexto e do referente" (DOLZ; PASQUIER; BRONCKART, 1993, p. 30, tradução nossa) e, portanto, associadas às "representações sobre o meio físico, sobre o tipo de interação que se processa (estatuto social dos participantes, instituição social em que o texto é produzido e os objetivos) e sobre os conhecimentos de mundo que podem ser mobilizados na produção de um texto" (MACHADO, 2003 , p. 217); 2) as capacidades discursivas, concebidas como "aptidões para mobilizar os modelos discursivos pertinentes a uma ação determinada" ${ }^{\prime \prime} \mathrm{e}, \log$, relacionadas à infraestrutura do texto (plano geral, tipos de discurso e tipos de sequência); 3) as capacidades linguístico-discursivas, consideradas "capacidades de domínio das múltiplas

2. Posteriormente, Dolz e Schneuwly (2011) substituíram a palavra texto por gênero, uma vez que todo texto se inscreve em determinado gênero.

3. aptitudes requises pour la réalisation d'un texte dans une situation d'interaction determinée (DOLZ; PASQUIER; BRONCKART, 1993, p. 30).

4. des aptitudes à adapter la production langagière aux caractéristiques du contexte et du référent" (DOLZ; PASQUIER; BRONCKART, 1993, p. 30).

5. aptitudes à mobiliser les modèles discursifs pertinents pour une action déterminée" (DOLZ; PASQUIER; BRONCKART, 1993, p. 30) . 
operações psicolinguísticas requeridas para a produção de um discurso singular" ${ }^{\prime \prime}$ e, assim, associadas às coerências temática e pragmática (DOLZ; PASQUIER; BRONCKART, 1993, p. 30, tradução nossa).

Além das capacidades de linguagem mencionadas, Cristovão e Stutz (2011) propõem as capacidades de significação, as quais "possibilitam ao indivíduo construir sentido mediante representações e/ou conhecimentos sobre práticas sociais (contexto ideológico, histórico, sociocultural, econômico, etc.)" relacionadas a conteúdos temáticos de diferentes experiências humanas nas suas relações com as atividades de linguagem (CRISTOVÃO; STUTZ, 2011, p. 22-23). Segundo Cristovão (2013), a criação dessa quarta capacidade se justifica pela necessidade de trabalho com aspectos mais amplos da atividade geral, dos gêneros textuais e do agir linguageiro materializado no texto, uma vez que, frequentemente, os materiais e práticas didáticas se limitam à busca de informações no âmbito textual, sem aprofundamento e produção de significação, isto é, sem suscitar reflexão sobre ideologias subjacentes, relações de poder, traços culturais, práticas sociais, etc.

As capacidades de significação demandam um olhar holístico na contemplação das atividades de linguagem e se desenvolvem por meio de um processo intersubjetivo, cujas operações cobrem o plano do discurso/ideologia e se aliam às capacidades de ação, discursivas e linguístico-discursivas (SOUZA; STUTZ, 2019). Tanto as capacidades de significação quanto as capacidades de ação pressupõem análises pré-textuais, ao passo que as capacidades discursivas e linguístico-discursivas privilegiam análises textuais (CRISTOVÃO; STUTZ, 2011). Em termos de nível hierárquico, as capacidades de significação envolveriam "o nível externo à unidade de comunicação da atividade imediata de linguagem, tendo como próximo nível as capacidades de ação, seguidas das discursivas, e, no menor nível, as linguístico-discursivas" (SOUZA; STUTZ, 2019, p. 1120). As capacidades de significação envolvem as seguintes operações de linguagem.

(1CS) Compreender as relações entre textos e a forma de ser, pensar, agir e sentir de quem os produz;

(2CS) Construir mapas semânticos;

(3CS) Engajar-se em atividades de linguagem;

(4CS) Compreender conjuntos de pré-construídos coletivos;

(5CS) Relacionar os aspectos macro com sua realidade;

(6CS) Compreender as imbricações entre atividades praxeológicas e de linguagem;

(7CS) (Re)conhecer a sócio-história do gênero;

(8CS) Posicionar-se sobre relações textos-contextos.

Quadro 1. Operações de linguagem das capacidades de significação

Fonte: Cristovão e Stutz (2011, p. 23).

Souza e Stutz $(2019$, p. 1120, 25) elucidam as oito operações de linguagem das capacidades de significação. A operação 1CS, ao enfocar a relação entre textos e a forma de ser, pensar, agir e sentir de quem os produz, possibilita o levantamento de hipóteses e o resgate de aspectos do mundo físico, psíquico e social relativo à atividade de linguagem. A operação 2CS trata dos mapas semânticos, que, conforme exposto anteriormente em Stutz (2012), "informa sobre os conhecimentos de ordem individual e coletiva com base nas escolhas de um campo lexical dada uma rota de informações possíveis, ou compreensão de segmentos de tratamentos temáticos". A operação 3CS envolve "o engajamento na produção e compreensão da atividade de linguagem dada uma visão holística da situação contextual e textual." As operações 4CS e 5CS visam "tecer relações dos pré-construídos coletivos advindos da atividade de linguagem quanto ao contexto macro e às interações com a realidade de quem as utiliza". A operação 6CS analisa "os modos de fazer advindos do olhar praxeológico com a linguagem que permeia as atividades". A operação 7CS se refere ao reconhecimento da sócio-história do gênero, a qual tem apoio "nas formas de representação da linguagem em eventos sociais e seus efeitos de comunicação em momentos e espaços anteriores, que orientam ou contribuem para o formato atualizado do gênero que se reconhece". A operação 8CS abrange "os posicionamentos quanto à atividade de linguagem com relação aos textos e os contextos em que atua".

Embora neste estudo nosso enfoque sejam as capacidades de significação, é importante destacar que as capacidades de linguagem operam de forma interligada.

6. capacités de maîtrise des multiplex opérations psycholinguistiques requises pour la production d'un discours singulier (DOLZ; PASQUIER; BRONCKART, 1993, p. 30). 


\section{METODOLOGIA}

Esta é uma pesquisa de natureza qualitativa devido à análise holística dos registros gerados de modo processual em sala de aula. Entre as possibilidades do paradigma qualitativo, o método de estudo de caso é adequado ao nosso objetivo de melhor compreender aspectos de ensino e aprendizagem no contexto específico das aulas de redação do projeto Pró-Imigrantes. No âmbito do estudo de caso, a professora regente implementou uma pesquisa-ação com o intuito de elevar a compreensão desses aspectos e intervir direta e ciclicamente no planejamento e ação que conduzissem à transformação de saberes almejada.

Destacamos que este artigo se trata do recorte de uma tese de doutorado (OLIVEIRA, 2019) e, assim, o conteúdo e análise nele apresentados se baseiam em discussões previamente tecidas no trabalho citado. Além disso, salientamos que autorização formal para a condução e publicação da pesquisa foi obtida junto ao Comitê de Ética da universidade a que a referida tese se vincula. Os três alunos participantes expressaram sua adesão por meio da assinatura de um Termo de Consentimento Livre e Esclarecido e escolheram nomes fictícios para protegerem suas identidades. Neste artigo, devido à limitação de espaço, enfocamos apenas a análise das produções textuais da aluna denominada Abigaël.

À época das aulas, Abigaël tinha 25 anos e trabalhava como auxiliar de cozinha em um restaurante de Belo Horizonte. É oriunda de Cabo Haitiano, cidade localizada no litoral norte do Haiti, tendo chegado ao Brasil em agosto de 2015; morava com a mãe, o padrasto e os irmãos na capital mineira. No Haiti, formou-se no equivalente ao Ensino Médio e fez um curso técnico na área de jornalismo. Em 2017, matriculou-se pelo segundo ano consecutivo no projeto Pró-Imigrantes, a fim de se preparar para o Enem. Atualmente, Abigaël cursa a faculdade de Farmácia em uma instituição particular.

Com o objetivo de ajudar os alunos a se preparem para a produção da redação do Enem, a professora elaborou um dispositivo inspirado na concepção de sequência didática (DOLZ; NOVERRAZ; SCHNEUWLY, 2011), a qual foi implementada entre março e agosto de 2017, totalizando 18 aulas com três horas de duração cada. Previamente, a professora elaborou um modelo didático da redação do Enem para definir as dimensões e características ensináveis do gênero textual a ser estudado (SCHNEUWLY; DOLZ, 2011; OLIVEIRA, 2019). As atividades dos sete módulos da sequência didática foram pensadas de acordo com as definições do modelo didático construído e as necessidades dos alunos em relação ao desenvolvimento das suas capacidades de linguagem.

Na primeira fase da sequência didática, realizamos a apresentação da situação, a qual ocupou as três primeiras aulas e possibilitou aos alunos terem contato com exemplares da redação do Enem, a fim de identificarem seu contexto de produção e características estruturais básicas antes de partirem para a sua efetiva escrita. Ademais, trabalhamos alguns conteúdos relevantes que pudessem ajudar os alunos a se posicionar sobre a temática em foco (A busca pelo equilíbrio entre consumo e sustentabilidade) e discutimos as orientações para a elaboração da redação contidas na cartilha do participante do Enem (BRASIL, 2016). Concluída essa fase, os alunos receberam uma proposta de redação (FIGURA 1), nos moldes do exame, e deram início à produção. 


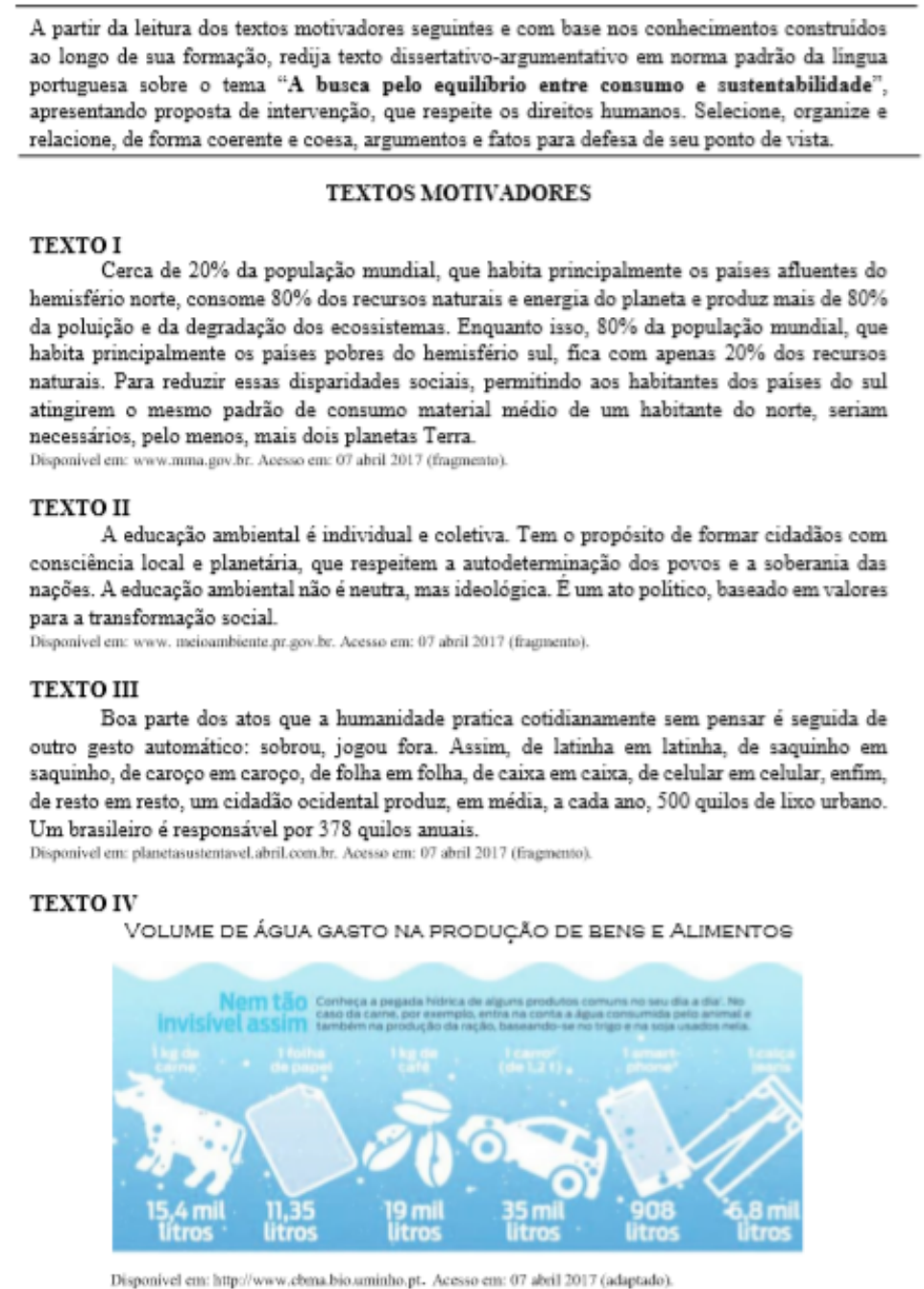

Figura 1. Proposta de redação

Fonte: Oliveira (2019)

Por meio da produção inicial verificamos as capacidades de linguagem que os alunos já dominavam satisfatoriamente e aquelas que ainda precisariam desenvolver. Embora diferentes capacidades de linguagem tenham sido desenvolvidas ao longo do trabalho com a sequência didática, neste artigo abordamos somente o desenvolvimento das capacidades de significação referentes aos textos de uma aluna. Mais especificamente, analisamos a mobilização das capacidades de significação para a construção da argumentação nas produções textuais.

Após o trabalho com seis módulos da sequência didática, dois dos quais enfocavam as capacidades de significação, os alunos reescreveram a produção inicial, dando origem à produção intermediária. Optamos pela escrita dessa versão devido à redação do Enem ser um gênero textual complexo e à constatação de que os alunos poderiam efetuar transformações adicionais nos textos, conforme o contínuo desenvolvimento das capacidades de linguagem, fortalecendo a natureza processual da aprendizagem. A escrita da produção final ocorreu após o trabalho com o módulo 7, o qual, entre outros aspectos, também visava ao desenvolvimento das capacidades de significação.

Para a análise da mobilização das capacidades de significação (CS) na construção da argumentação textual, baseamo-nos nas seguintes operações de linguagem, definidas por Cristovão e Stutz (2011): (1CS) compreender a relação entre textos e a forma de ser, pensar, agir e sentir de quem os produz; $(2 \mathrm{CS})$ construir mapas semânticos; (3CS) engajar-se em atividades de linguagem; $(4 \mathrm{CS})$ compreender conjuntos de pré-construídos coletivos; $(5 \mathrm{CS})$ relacionar os aspectos macro com sua realidade; $(6 \mathrm{CS})$ compreender as imbricações entre atividades praxiológicas e de linguagem; $(7 \mathrm{CS})$ (re)conhecer a sócio-história do gênero e (8CS) posicionar-se sobre as relações textoscontextos. 
O corpus de análise é composto de três produções escritas (inicial, intermediária e final) da aluna Abigaël e transcrições das aulas de redação gravadas em áudio. Também fazemos referência a algumas atividades dos módulos da sequência didática que enfocavam o desenvolvimento das capacidades de significação.

\section{ANÁLISE DOS REGISTROS}

Nesta seção, analisamos a mobilização das capacidades de significação para a construção da argumentação em três produções textuais de Abigaël, aluna do projeto Pró-Imigrantes e falante de português como língua adicional, realizadas no decorrer da implementação de uma sequência didática enfocada na redação do Enem e tendo como temática norteadora a busca pelo equilíbrio entre o consumo e a sustentabilidade. A seguir, apresentamos a produção inicial da aluna.

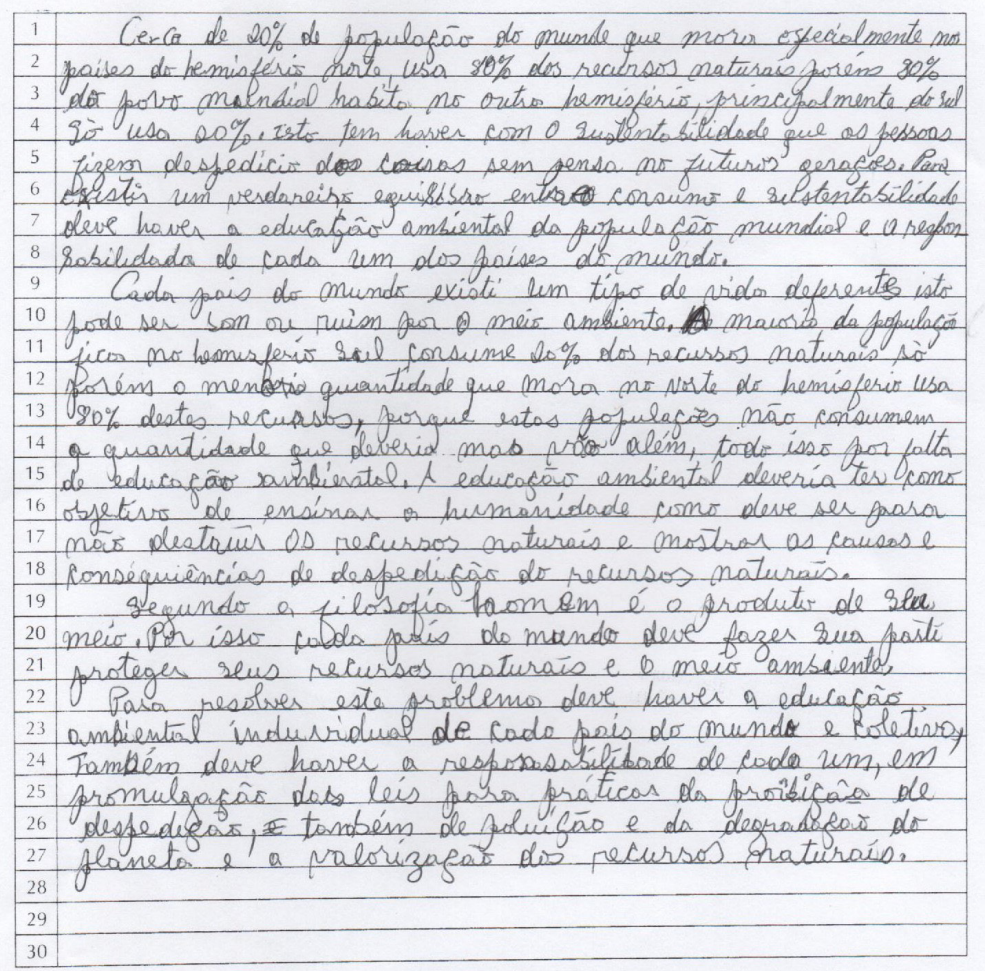

Figura 2. Produção inicial de Abigaël

Fonte: Oliveira (2019)

A produção inicial de Abigaël apresenta uma tese clara e objetiva: "Para existir um verdadeiro equilíbro (sic) entre consumo e sustentabilidade deve haver a educação ambiental da população mundial e a responsabilidada (sic) de cada um dos países do mundo" (linhas 5-8). Ao defender a necessidade de educação ambiental e a responsabilidade dos países para com a promoção do equilíbrio desejado - aspectos abordados na primeira fase da sequência didática e nos textos motivadores da proposta de redação (FIGURA 1) -, a aluna demonstra mobilizar as capacidades de significação, posicionando-se sobre relações textos-contextos (8CS). Também demonstra posicionamento ao argumentar que as pessoas não pensam nas futuras gerações ao praticarem o desperdício (linhas 4-5). Ao apresentar o desperdício como uma ação contrária à sustentabilidade (linhas 4-5), a aluna revela compreensão de conjuntos de pré-construídos coletivos (4CS).

Ainda no primeiro parágrafo (linhas 1-4), Abigaël faz referência, com certo equívoco ${ }^{7}$ e sem citação de fonte, a estatísticas apresentadas no primeiro texto motivador da proposta de redação (FIGURA 1), as quais contrastam

7. No texto motivador da proposta de redação, lê-se: "Cerca de $20 \%$ da população mundial, que habita principalmente os países afluentes do hemisfério norte, consome $80 \%$ dos recursos naturais" e " $80 \%$ da população mundial, que habita principalmente os países pobres do hemisfério sul, fica com apenas $20 \%$ dos recursos naturais". Já na produção inicial, afirma-se: "Cerca de $20 \%$ de população do munde (sic) que mora especialmente nos países do hemisfério norte, usa $80 \%$ dos recursos naturais" e "80\% do povo mundial habita no outro hemisfério, principalmente do sul só usa 20\%" (linhas 1-4). 
o consumo de recursos naturais entre as populações dos hemisférios norte e sul. A aluna repete as informações no segundo parágrafo (linhas 10-13), o que indica dependência em relação ao texto motivador. Ademais, emprega argumentos um tanto superficiais - por exemplo, "Cada país do mundo existi (sic) um tipo de vida diferente isto pode ser bom ou ruim por o meio ambiente" (linhas 9-10) -, o que aponta a necessidade de desenvolvimento das capacidades de significação para a construção de novos sentidos que favoreçam a argumentação. Mais adiante (linhas 14-18), Abigaël se posiciona novamente sobre relações textos-contextos (8CS) ao propor ser necessário que a educação ambiental tenha como objetivo ensinar a humanidade sobre as causas e consequências do desperdício e a não destruir os recursos naturais.

No terceiro parágrafo (linhas 19-21), Abigaël se volta para o segundo aspecto apontado em sua tese (linhas 7-8): a responsabilidade dos países em promover a sustentabilidade. Entretanto, a aluna parece ter dificuldades em mobilizar sentidos que a auxiliem na defesa dessa ideia, pois apenas emprega uma citação filosófica - "Segundo a filosofia homem é produto de seu meio" - sem estabelecer uma relação clara entre ela e a proposta de que "cada país do mundo deve fazer sua parte proteger seus recursos naturais e o meio ambiente" (linhas 20-21). A curta extensão do parágrafo também sugere que o trabalho com as capacidades de significação durante a sequência didática poderia contribuir para a argumentação na reescrita da produção inicial.

No último parágrafo (linhas 22-27), Abigaël elabora uma proposta de intervenção. Ao fazê-lo, a aluna se posiciona sobre o que acredita que deve ser feito para solucionar a problemática discutida (5CS e 8CS). Contudo, ocorre, majoritariamente, apenas a repetição de ideias já apresentadas nos parágrafos anteriores, sem o detalhamento necessário para esclarecer os agentes, as ações, os modos de implementação e as finalidades específicas dessas, conforme o modelo didático da redação do Enem mostrou ser necessário pormenorizar (OLIVEIRA, 2019; BRASIL, 2016). O desenvolvimento das capacidades de significação pode, em parte, ajudar na construção de conhecimentos relativos a intervenções adequadas para o alcance da sustentabilidade.

Ao elaborar a produção inicial, Abigaël se engajou em uma atividade de linguagem (3CS), por meio da qual se posicionou sobre relações textos-contextos (8CS), bem como demonstrou compreender conjuntos de préconstruídos coletivos (4CS). Ademais, a aluna, de forma indireta, relacionou aspectos macro com sua realidade (5CS) à medida que argumentou que a humanidade deve ter educação ambiental a fim de promover a sustentabilidade. A seguir, apresentamos a produção intermediária de Abigaël.

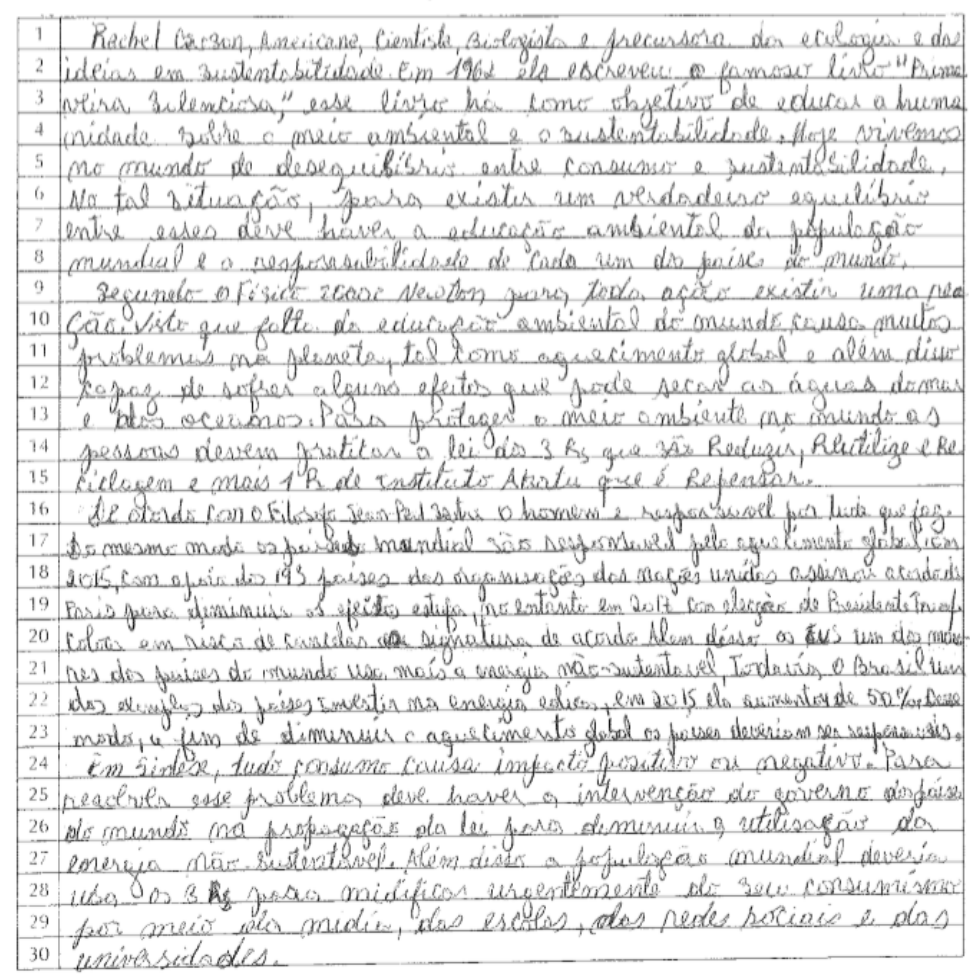

Figura 3. Produção intermediária de Abigaël

Fonte: Oliveira (2019) 
Abigaël se engaja novamente em uma atividade de linguagem (3CS) a fim de elaborar a reescrita da produção inicial. Na versão intermediária, a aluna opta por manter a tese apresentada no texto anterior, defendendo que para se alcançar o equilíbrio entre consumo e sustentabilidade deve haver a educação ambiental da população e responsabilidade por parte de cada país (8CS) (linhas 6-8). Ao afirmar que "Hoje vivemos no mundo de desequilíbrio entre consumo e sustentabilidade" (linhas 4-5), Abigaël relaciona aspectos macro com sua realidade (5CS), conforme depreendemos a partir do emprego do advérbio de tempo boje e do verbo viver na primeira pessoa do plural. A afirmação também configura uma tomada de posição sobre a realidade que nos cerca (8CS).

Como forma de contextualização do tema no início do primeiro parágrafo (linhas 1-4), a aluna faz alusão histórica à bióloga Rachel Carson, precursora das ideias em sustentabilidade, e seu livro Primavera Silenciosa, publicado em 1962 com o intuito de promover a educação ambiental. A alusão está diretamente relacionada à tese apresentada e resulta de novos sentidos construídos pela aluna por meio do trabalho com as capacidades de significação na sequência didática. No módulo 2, lemos e discutimos um texto sobre Rachel Carson e seu livro, o que possibilitou à aluna compreender a forma de pensar e agir da bióloga (1CS), relacionar a realidade da década de 1960 com a atual (5CS) e apoiar as ideias da cientista (8CS).

De maneira geral, a argumentação no primeiro parágrafo da produção intermediária se fortaleceu em relação à do texto anterior, sendo desenvolvida de maneira mais clara e aprofundada na temática em questão. Além disso, na produção intermediária, a aluna não se limitou a referenciar informações concedidas nos textos motivadores da proposta de redação (FIGURA 1); referências essas que na produção inicial foram feitas de forma repetitiva.

No segundo parágrafo, Abigaël dá continuidade à sua argumentação em favor da educação ambiental. Para tanto, emprega uma citação de Isaac Newton: "para toda ação existir (sic) uma reação" (linhas 9-10), a qual havia sido discutida durante o módulo 2, momento em que a professora pediu aos alunos que refletissem sobre a seguinte pergunta: embora a afirmação de Newton seja relativa a fenômenos da física, como vocês acham que ela poderia ser aplicada ao contexto do consumo e sustentabilidade? Apesar de apresentar dificuldades linguísticas para se expressar na escrita, Abigaël tenta relacionar ações humanas a reações negativas do meio ambiente (linhas 10-13). Ao argumentar nesse sentido, a aluna mobiliza as capacidades de significação, relacionando aspectos macro com sua realidade (5CS) e se posicionando sobre relações textos-contextos (8CS). As mesmas capacidades haviam sido mobilizadas em resposta à pergunta sobre a citação no módulo 2, conforme ilustram os seguintes excertos das transcrições ${ }^{8}$ das aulas gravadas em áudio (OLIVEIRA, 2019).

\section{Excerto 1}

01 Abigaël eu se- como (.) eu vou pegar o exemplo da publicidade (.) por exemplo a pessoa que

02

03

04

05

06

\section{Excerto 2}

$\begin{array}{lll}01 & \text { Abigaël } & \text { a natureza reage mais que as pessoas porque não tem ninguém que pode (.) } \\ 02 & \text { Goodson } & \text { impedir } \\ 03 & \text { Abigaël } & \text { impedir (.) só Deus (.) porque quando as pessoas deixa ela como posso dizer ( } \\ 04 & & \text { o camado de ozônio e você conhece que o sol vai ser muito (.) igual que um inferno (.) } \\ 05 & & \text { porque não tem não tem este camado pra poder pra proteger o sol o raio solar e as pessoas } \\ 06 & & \text { va- as pessoas vão (.) como posso dizer } \\ 07 & \text { Goodson } & \text { vão pagar as consequências } \\ 08 & \text { Abigaël } & \text { vai pagar }\end{array}$

Abigaël encerra o segundo parágrafo com o argumento de que, para proteger o meio ambiente, é necessário que as pessoas pratiquem a lei dos 3 R's (reduzir, reutilizar e reciclar), bem como ponham em prática o quarto $\mathrm{R}$

8. Convenções das transcrições adaptadas de Sacks, Schegloff e Jefferson (1974). 
(repensar), proposto pelo Instituto Akatu (linhas 13-15). Além de relacionar aspectos macro com sua realidade (5CS) e se posicionar sobre relações textos-contextos ( $8 \mathrm{CS}$ ), a aluna demonstra compreensão dos referidos princípios de educação ambiental como pré-construídos coletivos (4CS), discutidos no módulo 5. Em virtude da construção de novos sentidos possibilitada na sequência didática, o segundo parágrafo da produção intermediária apresenta argumentos mais fundamentados em relação ao parágrafo correspondente da produção inicial.

No terceiro parágrafo, o enfoque é a responsabilidade dos países quanto ao aquecimento global, aspecto diretamente relacionado à tese apresentada (linhas 6-8) e à temática do equilíbrio entre consumo e sustentabilidade. Abigaël cita o filósofo Jean-Paul Sartre ao afirmar que o homem é responsável por tudo o que faz (linha 16) e relaciona a citação à sua opinião pessoal de que "do mesmo modo" (linha 17) os países são responsáveis pelo aquecimento global (1CS, 5CS e 8CS). Conforme observamos no excerto 3 das transcrições das aulas gravadas em áudio (OLIVEIRA, 2019), a aluna havia expressado reflexões semelhantes ao responder às seguintes perguntas durante o trabalho com as capacidades de significação no módulo 2: vocês concordam ou discordam da afirmação de Sartre? Por quê?

\section{Excerto 3}

01 Abigaël às vezes sim o homem é responsável por tudo que faz (4.0) por exemplo (.) eu vou falar sobre a natureza se (2.0) se a gente não se cuidar bem da natureza vai (1.5) vai faltar água vai faltar muitas coisas no futuro mas se a- se a gente cuidar BEM da natureza no futuro vai ser (.) não vai ser perFElto porque vai ter falta mas não é muito que (2.0) que pode ( ) por exemplo se a gente corta as árvores e usa muito produto químico pra (3.0) pra queimar a camada de ozônio tudo isso a gente vai (.) vai pagar por isso porque na verdade o pagamento vai ser mal

Abigaël prossegue com sua argumentação fazendo alusão histórica ao Acordo de Paris, assinado em 2015 por diversos países (linhas 17-19). Provavelmente, a alusão é resultado do trabalho com as capacidades de significação no módulo 5, durante o qual lemos e discutimos um texto sobre o acordo e Abigaël teve a oportunidade de explicá-lo (4CS) em suas próprias palavras da seguinte maneira:

\section{Excerto 4}

01 Abigaël o acordo de paris é (.) um acordo que- que foi assinado pelas nações uni- pelas

02 organizações da- pelas organizações das nações unidas (.) pra proteger e (1.5) pra

$03 \quad$ proteger $(\quad)$ como posso dizer? a terra

04 Profa. isso mesmo (.) quantos países assinaram?

05 Abigaël 193

$\mathrm{Na}$ produção intermediária, a aluna também menciona a possibilidade de o presidente americano Donald Trump cancelar a participação dos Estados Unidos no acordo (linhas 19-20) e ressalta que o país é um dos maiores consumidores de energia não-sustentável, ao passo que o Brasil é um exemplo em termos de investimento em energia eólica (linhas 20-22). Ao mencionar práticas energéticas sustentáveis e não-sustentáveis dos dois países, Abigaël demonstra compreender conjuntos de pré-construídos coletivos (4CS) trabalhados no módulo 5 da sequência. Ademais, posiciona-se sobre relações textos-contextos (8CS) ao reafirmar a responsabilidade dos países em promover a sustentabilidade (linhas 22-23). Ao contrário do terceiro parágrafo da produção inicial, de curta extensão e desprovido de argumentos relacionados ao tema proposto, o terceiro parágrafo da produção intermediária apresenta informações, fatos e opiniões que em conjunto colaboram para a sustentação da argumentação.

Abigaël encerra a produção intermediária com uma proposta de intervenção para o problema discutido (5CS e 8CS), a qual, diferentemente da proposta elaborada na produção inicial, apresenta certo detalhamento. Para diminuir o impacto negativo do consumo de energia, a aluna propõe que os governos dos países aprovem leis em favor da redução do uso de energia não-sustentável (linhas 24-27). Além disso, sugere que a população em geral pratique o princípio dos 3 R's a fim de reduzir o consumismo (linhas 27-28). A aluna também faz referência à mídia, escolas, 
redes sociais e universidades com a provável intenção de destacá-las como agentes e meios para a consecução da proposta (linhas 29-30).

Conforme evidencia a análise da produção intermediária, Abigaël mobiliza as capacidades de significação desenvolvidas no decorrer do trabalho com a sequência didática, especialmente durante os módulos 2 e 5 , para o fortalecimento de sua argumentação sobre a temática do equilíbrio entre o consumo e a sustentabilidade. A seguir, apresentamos e analisamos a produção final elaborada.

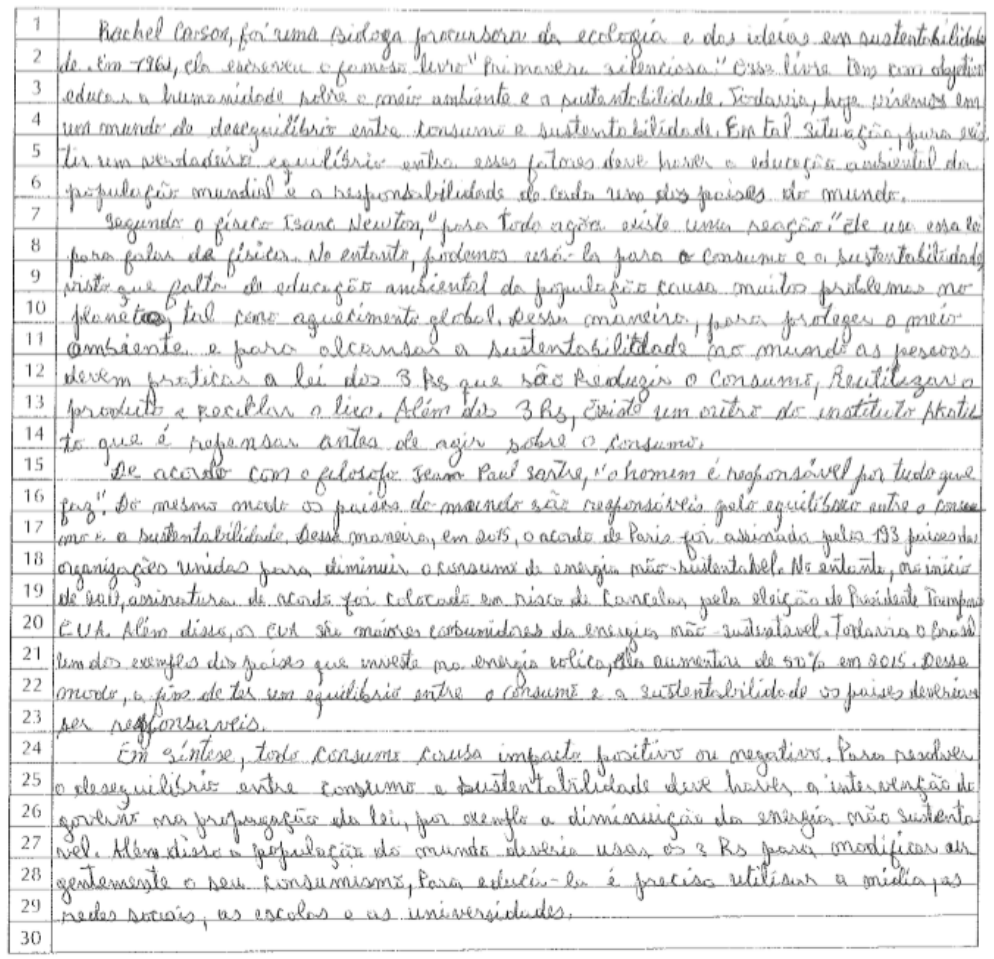

Figura 4. Produção final de Abigaël

Fonte: Oliveira (2019)

Abigaël produziu a versão final após o trabalho com o módulo 7, elaborado de forma personalizada para a aluna com base em aspectos problemáticos identificados na produção intermediária. Paralelamente, realizou atividades para a adequação do texto à modalidade escrita formal da língua portuguesa. Em razão do benefício de se incluir o próprio texto dos alunos em exercícios propostos (LIMA; SOUSA, 2016), tanto o módulo 7 como as demais atividades linguísticas traziam excertos da produção intermediária de Abigaël para serem analisados e aperfeiçoados.

Juntamente com outras capacidades de linguagem, as capacidades de significação continuaram a ser trabalhadas no módulo 7 e contribuíram para a elaboração da produção final. Por exemplo, a aluna estabelece, no segundo parágrafo (linhas 7-10), uma relação mais clara entre a citação de Isaac Newton e a temática em foco, afirmando que, embora Newton esteja se referindo a um princípio da física, podemos aplicar a citação à questão do consumo e sustentabilidade, visto que a falta de educação ambiental das pessoas provoca reações negativas no meio ambiente (1CS, 5CS e 8CS). Tal mobilização das capacidades de significação se deve, provavelmente, à reflexão promovida a partir das seguintes perguntas do módulo 7: Isaac Newton estava falando especificamente sobre consumo e sustentabilidade na citação acima? Como você pode deixar isso claro para o leitor e, ao mesmo tempo, conectar a citação ao tema?

Ainda no segundo parágrafo, Abigaël demonstra compreensão de pré-construídos coletivos (4CS) ao fornecer mais informações sobre os 3 R's, esclarecendo que se trata de "Reduzir o consumo, Reutilizar o produto e Reciclar o lixo" (linhas 12-13), além de "repensar antes de agir sobre o consumo" (linhas 14). No módulo 7, havíamos perguntado à aluna como ela poderia tornar o princípio dos 3 R's mais claro para o leitor.

Já no terceiro parágrafo, Abigaël realiza uma mudança de enfoque em relação ao parágrafo correspondente da produção intermediária (5CS e $8 \mathrm{CS}$ ). Enquanto nessa lemos que "os países mundial (sic) são responsavel (sic) pelo aquecimento global" (linha 17), na produção final lemos que "os países do mundo são responsáveis pelo equilíbrio 
entre o consumo e a sustentabilidade" (linhas 16-17). A aluna optou pela mudança para mais diretamente refletir a tese apresentada no primeiro parágrafo: "Em tal situação, para existir um verdadeiro equilíbrio entre esses fatores [consumo e sustentabilidade] deve haver a educação ambiental da população mundial e a responsabilidade de cada um dos países do mundo" (linhas 4-6). De forma semelhante, Abigaël alterou o trecho "diminuir os efeitos estufa", da produção intermediária (linha 19), para "diminuir o consumo de energia não-sustentável", na produção final (linha 18). Nos excertos 5 e 6, acompanhamos a reflexão da aluna durante o trabalho com o módulo 7 (OLIVEIRA, 2019).

\section{Excerto 5}
01 Profa.
o que você acha que tem que fazer?
02 Abigaël
eu acho que eu tenho que (2.5) que tirar aquecimento global e (2.0) e colocar um outras
03 palavras que- que tem mais relação com o consumo e sustentabilidade
04 Profa. e que palavras são essas?
05 Abigaël
(8.5) pode ser o mesmo consumo e sustentabilidade

Excerto 6

$\begin{array}{lll}01 & \text { Profa. } & \text { como que o acordo de paris ia diminuir o efeito estufa (.) o que os países precisavam } \\ 02 & & \text { fazer pra diminuir o efeito estufa? } \\ 03 & \text { Abigaël } & \text { diminuir o consu- o consumo } \\ 04 & \text { Profa. } & \text { o consumo de quê? } \\ 05 & \text { Abigaël } & \text { de }(4.5) \text { o consumo de }(2.5) \text { de energia não sustentável }\end{array}$

Por fim, Abigaël esclarece a proposta de intervenção que havia elaborado na produção intermediária, afirmando, na versão final (linhas 28-29), que "Para educá-la [a população do mundo] é preciso utilisar (sic), a midía (sic), as redes sociais, as escolas e as universidades" (5CS e 8CS). A análise da produção final revela a contínua mobilização das capacidades de significação. Em conjunto, as três versões do texto evidenciam um processo de construção de novos sentidos que contribuiu, de modo expressivo, para o fortalecimento da argumentação de Abigaël.

\section{CONSIDERAÇÕES FINAIS}

A partir da necessidade de promover o ensino e a aprendizagem da redação do Enem no contexto do projeto Pró-Imigrantes, foi implementado um dispositivo didático, semelhante à concepção de sequência didática (DOLZ; NOVERRAZ; SCHNEUWLY, 2011), com enfoque no desenvolvimento das capacidades de linguagem para a produção do referido gênero textual. Nesse processo, trabalhou-se, em especial, o desenvolvimento das capacidades de significação (CRISTOVÃO; STUTZ, 2011), na expectativa de que esse cooperaria para que os alunos superassem a dificuldade de se posicionar e argumentar sobre a temática proposta. Neste artigo, centralizamo-nos na análise da mobilização das capacidades de significação nos textos elaborados pela aluna Abigaël.

Verificamos que a mobilização das capacidades de significação contribuiu, de modo expressivo, para o fortalecimento da argumentação nas produções textuais da aluna, as quais evidenciam as seguintes operações de linguagem (CRISTOVÃO; STUTZ, 2011): (1CS) compreender as relações entre textos e a forma de ser, pensar,

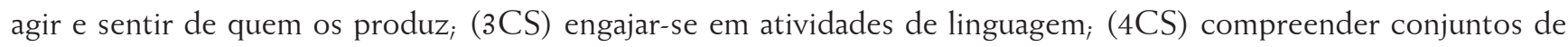
pré-construídos coletivos; $;$ (5CS) relacionar os aspectos macro com sua realidade; $(8 \mathrm{CS})$ posicionar-se sobre relações textos-contextos. A operação $8 \mathrm{CS}$ é uma das mais recorrentes nas análises efetuadas, provavelmente em consequência da natureza dissertativo-argumentativa da redação do Enem, a qual exige que o produtor expresse sua opinião e a defenda. A operação 5CS também se destaca, porém é mobilizada de maneira um tanto indireta em razão de a redação do Enem ter como característica, constatada no modelo didático elaborado para o gênero, o favorecimento da impessoalidade por meio, por exemplo, do emprego da terceira pessoa do singular e plural (OLIVEIRA, 2019).

É importante ressaltar que as demais operações de linguagem das capacidades de significação (2CS, 6CS e 7CS) não foram diretamente trabalhadas na sequência didática implementada, o que não impede que elas tenham sido mobilizadas pela aluna. No entanto, em nossa análise, enfocamos as operações intencionalmente trabalhadas e desenvolvidas no decorrer da intervenção pedagógica. 
Uma vez que o desenvolvimento das capacidades de significação se mostrou essencial para que a aluna fortalecesse a argumentação em seus textos, este estudo corrobora a proposta de Cristovão e Stutz (2011) de articulálas às demais capacidades de linguagem (DOLZ; PASQUIER, BRONCKART, 1993). Conforme as autoras atestam, há a necessidade de ampliação do trabalho com os gêneros textuais no sentido de suscitar o aprofundamento e produção de significação, ou seja, a reflexão sobre aspectos ideológicos, culturais, sociais, entre outros que extrapolam o nível da arquitetura textual, mas influenciam, inextricavelmente, a atividade de linguagem (CRISTOVÃO; STUTZ, 2011; CRISTOVÃO, 2013).

Este estudo também contribui para a área de Português como Língua de Acolhimento devido ao contexto em que está inserido e à apresentação de uma intervenção pedagógica que favorece "a circulação de saberes linguísticodiscursivos que, em última instância, contribuam para 'produzir e democratizar mobilidades e multiterritorialidades', fazendo face a processos de 'reterritorialização precária'", (LOPEZ; DINIZ, 2018, p. 37: BIZON, 2013, p. 123). No cenário atual, o Brasil se configura como país de destino para milhares de imigrantes, o que tem tornado discussões sobre o acesso dessa população ao ensino superior cada vez mais relevantes. Rezende (2010), ao investigar a constituição identitária de refugiados em São Paulo, e São Bernardo (2016), ao analisar depoimentos de imigrantes de um curso de PLAc em Brasília, verificaram o frequente anseio por uma formação universitária associado ao vislumbre de uma vida melhor na sociedade de acolhimento. Mais recentemente, Camargo (2019, p. 142), ao ouvir vários atores de políticas públicas de acolhimento em São Paulo, observou que a educação é narrada como um "forte possibilitador dos processos de reterritorialização" dos migrantes de crise, havendo aqueles que desejam aprender português para fins específicos, tal qual o de participação no Enem.

A participação no Enem se faz necessária para o ingresso em grande parte das instituições públicas de ensino superior. Ademais, os resultados no exame também podem ser utilizados para ingresso em muitas instituições acadêmicas privadas. Algumas universidades públicas têm estabelecido processos seletivos específicos para refugiados e outros migrantes de crise, sendo que em alguns deles, como no caso da Universidade Federal de Minas Gerais e da Universidade Federal de São Carlos, as notas obtidas no Enem são utilizadas como critério seletivo. A escrita da redação do Enem é bastante desafiadora, principalmente para migrantes de crise falantes de português como língua adicional. Este estudo apresenta uma possível abordagem, por meio do desenvolvimento das capacidades de significação, com vistas a auxiliá-los na preparação para esse desafio. Contudo, uma vez que a prova de redação do Enem é elaborada especificamente para falantes de português como língua materna que tenham cursado o Ensino Médio no Brasil, é importante ressaltar, conforme Oliveira (2019), que a sua utilização em processos seletivos que envolvam migrantes de crise falantes de português como língua adicional pode não ser a mais adequada.

\section{REFERÊNCIAS}

ACNUR. (2020). Alto Comissariado das Nações Unidas para os Refugiados. Global trends: forced displacement in 2019. Disponível em: $\quad<$ https://www.unhcr.org/news/press/2020/6/5ee9db2e4/1-cent-humanity-displaced-unhcr-global-trends-report. html>. Acesso em: 29 out. 2020.

BIZON, A. C. C. (2013). Narrando o exame Celpe-Bras e o convênio PEC-G: a construção de territorialidades em tempos de internacionalização. Tese de Doutorado em Linguística Aplicada. Instituto de Estudos da Linguagem, Unicamp, Campinas.

BIZON, A. C. C; CAMARGO, H. R. E. Acolhimento e ensino da língua portuguesa população oriunda de migração de crise no município de São Paulo: por uma política do atravessamento entre verticalidades e horizontalidades. In: BAENINGER, R. et al. (Org.). Migrações Sul-Sul. Campinas: Núcleo de Estudos de População "Elza Berquó" - Nepo/Unicamp, 2018.

BRASIL. (2016). Instituto Nacional de Estudos e Pesquisas Educacionais Anísio Teixeira. Ministério da Educação. Redação no Enem 2016: cartilha do participante. Brasília: Inep/MEC. Disponível em: <http://download.inep.gov.br/educacao_basica/ enem/guia_participante/2016/manual_de_redacao_do_enem_2016.pdf >. Acesso em 29 out. 2020.

BRONCKART, J. P. (1999). Atividade de linguagem, textos e discursos. Por um interacionismo sócio-discursivo. Tradução de Anna Rachel Machado, Péricles Cunha. São Paulo: EDUC. 
BRONCKART, J. P. (2006). Atividade de linguagem, discurso e desenvolvimento bumano. Tradução de Anna Rachel Machado, Maria de Lourdes Meirelles Matencio. Campinas: Mercado de Letras.

CAMARGO, H. R. E. (2019). Diálogos transversais: narrativas para um protocolo de encaminhamentos para políticas de acolhimento a migrantes de crise. Tese de Doutorado em Linguística Aplicada. Instituto de Estudos da Linguagem, Unicamp, Campinas.

CRISTOVÃO, V. L. L. (2013). Para uma expansão do conceito de capacidades de linguagem. In: BUENO, L.; LOPES, M. A. P. T.; CRISTOVÃO, V. L. L (Org.). Gêneros textuais e formação inicial: uma homenagem à Malu Matencio. Campinas: Mercado de Letras, pp. 357-383.

CRISTOVÃO, V. L. L.; STUTZ, L. (2011). Sequências didáticas: semelhanças e especificidades no contexto francófono como L1 e no contexto brasileiro como LE. In: SZUNDY, P. T. C., et al. (Org.). Linguística aplicada e sociedade: ensino e aprendizagem de línguas no contexto brasileiro. Campinas: Pontes, pp. 17-40.

DOLZ, J.; GAGNON, R.; DECÂNDIO, F. (2010). Produção escrita e dificuldades de aprendizagem. Campinas: Mercado de Letras.

DOLZ, J.; NOVERRAZ, M.; SCHNEUWLY, B. (2011). Sequências didáticas para o oral e a escrita: apresentação de um procedimento. In: SCHNEUWLY, B.; DOLZ, J. Gêneros orais e escritos na escola. Trad. e org. Roxane Rojo, Glaís Sales Cordeiro. Campinas: Mercado de Letras, pp. 81-108.

DOLZ, J. PASQUIER, A. BRONCKART, J. P. (1993). L'acquisition des discours: émergence d'une competence ou apprentissage de capacités langagières diverses? Études de Linguistique Appliquée, n. 92, pp. 23-37.

DOLZ, J. SCHNEUWLY, B. (2011). Gêneros e progressão em expressão oral e escrita - elementos para reflexões sobre uma experiência suíça (francófona). In: SCHNEUWLY, B.; DOLZ, J. Gêneros orais e escritos na escola. Trad. e org. Roxane Rojo, Glaís Sales Cordeiro. Campinas: Mercado de Letras, pp. 35-59.

LIMA, P. S. SOUSA, I. V. (2016). Produção de artigo de opinião em sequência didática. In: SILVA, W. R., et al. (Org.). Gêneros na prática pedagógica: diálogos entre escolas e universidades. Campinas: Pontes, pp. 167-197.

LOPEZ, A. P. A. (2016). Subsídios para o planejamento de cursos de Português como Língua de Acolbimento para imigrantes deslocados forçados no Brasil. Dissertação de Mestrado em Linguística Aplicada. Faculdade de Letras, UFMG, Belo Horizonte.

LOPEZ, A. P. A.; DINIZ, L. R. A. Iniciativas jurídicas e acadêmicas brasileiras para o acolhimento de deslocados forçados. Revista da Sociedade Internacional Português Lingua Estrangeira (SIPLE), v. 9, p. 31-56, 2018.

MACHADO, A. R. (2003). Os textos de alunos como índices para a avaliação das capacidades de linguagem. In: MARI, H.; MACHADO, I. L; MELLO, R. (Org.). Análise do discurso em perspectivas. Belo Horizonte: UFMG, 2003. pp. 215-229.

MARCUSCHI. L. A. (2011). Gêneros textuais: configuração, dinamicidade e circulação. In: KARWOSKI, A. M.; GAYDECZKA, B.; BRITO, K. S. (Org.). Gêneros textuais: reflexões e ensino. São Paulo: Parábola, pp. 17-31.

OLIVEIRA, D. A. (2019). A preparação de imigrantes baitianos para a produção da redação do Enem. Tese de Doutorado em Estudos Linguísticos. Faculdade de Letras, UFMG, Belo Horizonte.

REZENDE, P. S. (2010). A constituição identitária de refugiados em São Paulo: moradias na complexidade do ensino-aprendizagem de português como língua estrangeira. Tese de Doutorado em Linguística Aplicada e Estudos da Linguagem. PUC-SP, São Paulo.

SÃO BERNARDO, M. A. (2016). Português como língua de acolbimento: um estudo com imigrantes e pessoas em situação de refúgio no Brasil. Tese de Doutorado em Linguística. Centro de Educação e Ciências Humanas, UFSCar, São Carlos.

SCHNEUWLY, B.; DOLZ, J. (2011). Gêneros escolares: das práticas de linguagem aos objetos de ensino. In: SCHNEUWLY, B.; DOLZ, J. Gêneros orais e escritos na escola. Trad. e org. Roxane Rojo, Glaís Sales Cordeiro. Campinas: Mercado de Letras, pp. $61-78$. 


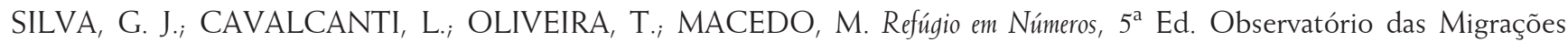
Internacionais; Ministério da Justiça e Segurança Pública/Comitê Nacional para Refugiados. Brasília, DF: OBMigra, 2020.

SOUZA, E. G. G.; STUTZ, L. (2019). O (re)conhecimento da sócio-história nas capacidades de significação: conceitos necessários para operacionalização de linguagem e didatização de gêneros. Trabalhos em Linguística Aplicada, v. 58, n. 3, pp. 1113-1133.

STUTZ, L. (2012). Sequências didáticas, socialização de diários e autoconfrontação: instrumentos para a formação inicial de professores de inglês. Tese de Doutorado em Estudos da Linguagem. Centro de Letras e Ciências Humanas, UEL, Londrina.

Recebido: 18/5/2020

Aceito: $13 / 10 / 2020$

Publicado: 28/6/2021 